\title{
Uma leitura além da margem: diálogos entre a escrita de Lima Barreto e o hip hop de Emicida nos entornos da sala de aula
}

\author{
A reading beyond the margin: dialogues between Lima Barreto's writing and \\ Emicida's hip hop in the classroom environment
}

Recebido em: 30/08/2017
Aprovado em: 02/05/2019
Publicado em: 30/07/2019

\section{Ana Paola Laeber ${ }^{1}$ Poliana da Silva Carvalho ${ }^{2}$}

\begin{abstract}
Resumo: O presente trabalho objetiva-se em aprimorar os estudos literários a partir da escrita de Lima Barreto, escritor pré-modernista que buscou retratar os modos de vida dos subúrbios cariocas e de sua população, e de Emicida, rapper considerado como uma das maiores revelações musicais de hip hop do Brasil nos últimos anos. Ambos literatos negros, embora pertencentes a uma mesma nação - Brasil, constituíram (e constituem) por meio de suas obras um amplo painel da sociedade na qual estavam inseridos, jamais abdicando do que era a função maior da literatura: intervir nas questões de seus tempos, expondo, por meio de suas subjetividades, um discurso para aqueles que são atormentados pela intolerância social. Tendo como mote trechos da obra póstuma "Diário íntimo" de Lima Barreto e o rap "Boa Esperança" de Emicida, procuraremos entender o modo como esses dois enunciadores fizeram de suas produções literárias uma prática de intervenção nas questões urbanas e sociais em épocas distintas, na dupla dimensão de escritores e cidadãos, e como seus textos podem ser trabalhados nos entornos da sala de aula, proporcionando aos discentes momentos de reflexão crítica e sensibilização aos problemas vigentes em nossa sociedade.
\end{abstract}

Palavras-chave: Lima Barreto; Emicida; Análise do Discurso; Sala de aula; Literatura.

Abstract: The present work aims at improving literary studies based on the writing of Lima Barreto, a pre-modernist writer who sought to portray the ways of life of the Carioca suburbs and their population, and of Emicida, a rapper considered one of the greatest musical revelations of hip hop in Brazil in recent years. Both black literates, although belonging to the same nation - Brazil, constituted (and constitute) through their works a broad panel of the society in which they were inserted, never giving up what was the major function of literature: intervening in the questions of their times, exposing, through their subjectivities, a discourse for those who are tormented by social intolerance. Taking as its motto excerpts from the posthumous work "Diário íntimo" by Lima Barreto and the rap "Boa Esperança" by Emicida, we will try to understand how these two enunciators have made their literary productions a practice of intervention in urban and social issues at different times, In the double dimension of writers and citizens, and how their texts can be worked in the classroom environment, providing students with moments of critical reflection and awareness of the problems in our society.

Keywords: Lima Barreto; Emicida; Speech analysis; Classroom; Literature.

1.Graduação em Licenciatura Plena em Letras com habilitação em Língua Portuguesa, Língua Inglesa. Especialista em Educação Profissional Técnica Integrada ao Ensino Médio na EJA. Mestre em Letras. ORCID: 0000-0003-3857-2162 Email: ana.laeber@ifes.edu.br

2. Licenciada em Letras - Português/Espanhol pelo Centro Universitário São José de Itaperuna (UNIFSJ); Especialista em Estudos de Língua Portuguesa e Literatura Brasileira pelo Centro Universitário São José de Itaperuna (UNIFSJ); Mestre em Cognição e Linguagem pela Universidade Estadual do Norte Fluminense Darcy Ribeiro (Uenf). ORCID: 00000003-4763-5516 E-mail: poliana.carvalho@ifes.edu.br 


\section{INTRODUÇÃO}

Quando comecei a escrever este, uma "esperança" pousou.

(Lima Barreto)

"Sou porta-voz de quem nunca foi ouvido Os esquecido lembra de mim porque eu lembro dos esquecido"

(Emicida)

Afonso Henriques de Lima Barreto, mais conhecido por Lima Barreto, teve a maior parte de sua obra redescoberta e publicada em livro após sua morte. "Diário íntimo1" é apenas uma de suas obras póstumas. Escritor pré-modernista, Lima Barreto buscou retratar os modos de vida dos subúrbios cariocas. Ele e Emicida são literatos negros, pertencem a uma mesma nação, Brasil, constituíram - e constituem - por meio de suas obras um amplo painel da sociedade na qual estavam (estão) inseridos, jamais abdicando do que era a função maior da literatura: intervir nas questões de seus tempos, expondo, por meio de suas subjetividades, um discurso para aqueles que são atormentados pela intolerância social.

Tendo como mote a obra "Diário íntimo" de Lima Barreto e o rap "Boa² Esperança" de Emicida, procuraremos entender o modo como esses dois enunciadores fizeram de suas produções literárias uma prática de intervenção nas questões urbanas e sociais em épocas distintas, na dupla dimensão de escritores e cidadãos. Para isso, delineamos os seguintes objetivos: demonstrar a estreita relação de "Diário Íntimo" com aspectos de vida no rap "Boa Esperança" de Emicida; compreender as escolhas estéticas e reflexivas de Lima Barreto e Emicida, bem como a recepção de suas obras - passada e contemporânea - sem deixar de relacioná-las com o contexto histórico; e estabelecer uma análise comparativo-discursiva entre a obra em questão de Lima Barreto e o rap "Boa Esperança" de Emicida, tendo em vista que ambos militaram a partir de uma literatura rica e combativa, que deu voz às minorias.

\footnotetext{
${ }^{1}$ A análise da obra "Diário Íntimo" e do rap "Boa Esperança" partiu do encontro das turmas dos $2^{\circ} \mathrm{S}$ anos do curso técnico em Meio Ambiente e em Florestas, realizado pela Comissão responsável pela Semana da Consciência Negra, referente ao ano de 2016, no Ifes Campus Ibatiba de acordo com a Portaria №. 363, de 11 de novembro de 2016.

2 O rap, dentro do movimento hip-hop, chegou no Brasil na década de 80 , notadamente na periferia. Com as canções, muitos rappers adotaram o movimento como modo de denunciar as desigualdades sofridas por aqueles que estão na considerada "margem da sociedade" (SUSIN, 2015).
} 


\section{LAEBER, AP}

Nosso método para esse estudo é a pesquisa bibliográfica, com leitura reflexiva e investigativa, seguida de análise e interpretação da obra póstuma "Diário íntimo" (1953), de Lima Barreto, e o rap "Boa Esperança", de Emicida. A discussão acerca da obra "Diário Íntimo" servirá como base para que se estude a sociedade brasileira e como esta se vê e é vista, sobretudo no que diz respeito aos problemas sociais.

A proposta é desenvolvida com embasamento teórico advindo da Análise do Discurso Francesa (ADF) e fundamentada, principalmente, nos textos de Orlandi (2005), e para as análises discursivas citamos Barreto (2001) e Emicida (2009).

Concluiremos por meio da discussão dos dados em confronto com fontes históricas e análises de pesquisas anteriores sobre estes textos, explicitando como esses textos literários podem ser trabalhados nos entornos da sala de aula com enfoque na leitura subjetiva dos alunos, isto é, a leitura que cada um faz acerca dos textos lidos, proporcionando-Ihes momentos de reflexão crítica, ressignificação dos textos e sensibilização aos problemas vigentes em nossa sociedade.

\section{Um breve estudo: análise do discurso francesa (ADF)}

A Análise do Discurso (AD) é um dos ramos da Linguística - ciência da linguagem cujo interesse é a investigação da língua em situações reais de uso - que considera que o ato comunicativo obedece a um contrato estabelecido pelos interlocutores envolvidos numa interação específica. Ela surgiu na década de 60 na França, por Michel Pêcheux e Jean Dubois marcando uma tríade em conexão com a linguística, o marxismo e a psicanálise, e tendo o discurso como objeto de estudo.

Ao se propor estudar o discurso, a AD busca ver a língua não apenas como transmissão de informações ou o simples ato de fala, mas a língua numa visão discursiva que busca a exterioridade da linguagem como a ideologia e o fator social.

Orlandi (2005), ao discorrer sobre o objetivo da AD, menciona que a ela toma a linguagem como mediadora indispensável entre o homem e o meio social e natural em que vive: "o discurso é a palavra em movimento, em prática de linguagem; com o estudo do discurso observa-se o homem falando" (ORLANDI, 2007, p.15). Assim, a AD não toma a língua como um sistema abstrato, mas a língua como método de interação. Segundo a supracitada autora,

O discurso é a materialidade específica da ideologia e a língua é a materialidade específica do discurso. Desse modo temos a relação entre 
língua e ideologia afetando a constituição do sujeito e do sentido. Resta dizer que sujeito e sentido se constituem ao mesmo tempo. É pelo fato mesmo de dizer que o sujeito se diz, se constitui (2006, p. 17).

Ao tomarmos como mote a obra de Lima Barreto, "Diário Íntimo" (1953) e o rap de Emicida (2015), "Boa Esperança”, levamos em consideração como o contexto (social e sala de aula) e os respectivos autores supracitados vivenciaram o tema principal, 0 preconceito racial e social, uma vez que Orlandi (1996, p. 17) diz que "o estudo da linguagem não pode estar apartado da sociedade que a produz, pois os processos que entram em jogo na constituição da linguagem são processos histórico-sociais".

Isso significa que cada discurso é carregado de ideologias que cada indivíduo carrega consigo. Para Pêcheux (1997 apud SOUZA e FACHIN) "não há discurso sem sujeito e não há sujeito sem ideologia3; o indivíduo é interpelado em sujeito pela ideologia e é assim que a língua faz sentido". Tomando como base as teses althusserianas, Pêcheux rediscute a abordagem do sujeito pela ideologia:

Naquilo que concerne à ideologia, corresponde ao fato de que os aparelhos ideológicos do estado são, por sua própria natureza plurais: eles não formam um bloco ou uma lista homogênea, mas existem dentro de relações de contradição desigualdade-subordinação tais que suas propriedades regionais (sua especialização... nos domínios da religião, do conhecimento, da moral, do direito, da política, etc) contribuem desigualmente para o desenvolvimento da luta ideológica entre as duas classes antagonistas, intervindo desigualmente na reprodução ou na transformação das condições de produção (PÊCHEUX, 2000, p. 9).

Como mencionado anteriormente, Michel Pêcheux foi um dos precursores da Análise do Discurso Francesa (ADF), o qual concedeu uma base teórico-metodológica para o desenvolvimento da AD. Para construir a noção de discurso, Pêcheux baseia-se criticamente em Saussure, reconhecendo nele o ponto de origem da ciência Linguística.

Enquanto ciência, a AD possui corpo de doutrina que lhe garante instrumentos de análise e quadro teórico-metodológico próprios. Sua finalidade é analisar os efeitos produzidos por meio da língua. Trata-se do estudo do sentido social construído na comunidade. Uma de suas contribuições é mostrar como se estrutura discursivamente o social.

Segundo Pêcheux (apud MUSSALIM, 2006),

${ }^{3}$ Para Althusser (1992, p. 23) "a ideologia exprime sempre, seja qual for a sua forma (religiosa, jurídica, política) posições de classe. 
a Análise do Discurso como uma forma de determinar as condições que são usadas para a produção de um texto, a maneira de avaliar a leitura do mesmo, como os protagonistas se inserem no discurso e como se relacionam. Ainda em Pêcheux, verifica-se que em um discurso é essencial a relação locutor/ouvinte valorizando a ideologia do discurso.

Dessa forma, entende-se que o discurso preconizado por Lima Barreto e Emicida em suas literaturas transcende a materialidade das palavras em si e faz de suas produções literárias uma prática de intervenção nas questões urbanas e sociais em épocas distintas.

\section{Análise das obras "DIÁRIO ÍNTIMO" e "BOA ESPERANÇA"}

O nosso objetivo aqui é traçar a trajetória de Lima Barreto e sua escrita na obra póstuma "Diário Íntimo", do Pré-Modernismo, e estudar o escritor em relação aos movimentos sociais, além de trazer à tona uma discussão profícua da composição "Boa Esperança" do rapper Emicida em sala de aula. Espera-se que o estudo dessas obras forneça dados interessantes sobre a sociedade da época de Lima Barreto e da sociedade contemporânea, estritamente ligadas aos movimentos sociais.

Assim, os trechos de "Diário Íntimo" servirão de base para que os nossos alunos entendam como o percurso infeliz da trajetória de vida do romancista pré-modernista Lima Barreto influenciou sua escrita. Ainda tão atual, Emicida (Leandro Roque) em "Boa Esperança”, com sua letra, aponta como um problema tão grave como a discriminação, o preconceito, tanto racial e social, acontece diariamente em nossa sociedade.

A escolha dos dois gêneros textuais no contexto escolar foi devido às vozes sociais inseridas no rap (canção) e diário, que adota (nem sempre) um tom autobiográfico, e também possui um valoroso documento histórico. Esses gêneros em sua diversidade e oriundos de épocas diferentes formam um novo discurso, uma nova linguagem. Dessa forma Bakhtin nos explica que

Os elementos da língua dentro do sistema da língua ou dentro do "texto" (no sentido rigorosamente linguístico) não podem entrar em relações dialógicas. As línguas, dialetos (territoriais, sociais, gírias), estilos de linguagem (funcionais), digamos o discurso familiar do cotidiano e a linguagem cientifica, podem entrar naquelas relações dialógicas. Isto 'e, conversar entre si? Sósob a condição de um enfoque linguístico, isto 'e, de serem transformados em "visões de mundo" (ou em certas visões de mundo centradas na linguagem ou no discurso), em "pontos de vista", em "vozes sociais", etc. (2003, p. 325). 


\section{LAEBER, AP}

Da mesma forma que a escrita barretiana, em forma de diário, demonstra uma literatura militante, termos como proposta juntamente a análise do rap, e, principalmente do compositor Emicida, nos possibilita trazer à tona questões socioculturais que ainda são consideradas como estereótipos.

\section{A importância da escrita de Lima Barreto no contexto da sala de aula}

A obra de Lima Barreto, "Diário Íntimo", publicada postumamente, é um emaranhado de várias anotações como projetos de (futuros) romances, observações do cotidiano carioca, críticas literárias, recortes de jornal, acontecimentos particulares, íntimos. Por isso, pode-se dizer que é um livro híbrido.

A escolha dessa obra deu-se justamente por se tratar de um gênero textual (diário) que nos coloca diante da expressão da subjetividade do autor/escritor, bem como suas angústias, indignações, sofrimentos ou até mesmo seus momentos de felicidade e êxito.

Hidalgo (2008, p. 51) nos diz que "o diário pode ser lido como o esforço da reconstrução de fragmentos do eu, organização de delírios e pensamentos, entre outras finalidades". Por sua vez, Foucault (1992) tomou como base a vida do santo que viveu de 295 a 373, Atanásio, como elemento indispensável para fazer uma análise da escrita de si. Para o filósofo francês, ao classificar as escritas dos séculos I e II como correspondência e hypomnemata, nos diz que, embora os hypomnemata podiam ser livros de contabilidade, registros notariais, cadernos pessoais que serviam de agenda (1992), Foucault diferenciou esses dos diários íntimos por não compor uma narração de si.

Voltando a obra de Lima Barreto, quanto à responsabilidade de organizar e publicar, o biógrafo Francisco de Assis Barbosa reuniu todas essas anotações escritas entre os anos de 1900 a 1921, com o intuito de promovê-lo, adotando um viés autobiográfico.

Hoje, pois, como não houvesse assunto, resolvi fazer dessa nota uma página íntima, tanto mais íntima que é de mim para mim, do Afonso de vinte e três anos para o Afonso de trinta, de quarenta, de cinquenta anos. Guardando-as, eu poderei fazer delas como pontos determinantes da trajetória da minha vida e do meu espírito, e outro não é o meu fito (BARRETO, 2011, p. 12). 


\section{LAEBER, AP}

Pensar a sociedade na época de Lima Barreto é considerar, especialmente, o Rio de Janeiro, capital do Brasil no início do século XX. Nesse contexto histórico nasce Lima Barreto, mais especificamente em 13 de maio de 1881, segundo filho de pais pobres e mestiços. Era filho de João Henriques de Lima Barreto, tipógrafo, e Amalia Augusta, professora. A Lei Áurea seria assinada quando Lima completasse 7 anos. Mesmo assim, Afonso Henriques e toda a sua família estariam à mercê de uma sociedade preconceituosa.

Lima Barreto apresentou traços depressivos logo no início de sua breve vida. De acordo com Barbosa (1988, p. 29), o falecimento precoce da mãe, deixaria um grande vazio na alma deste menino "taciturno, reservado e tímido". Barreto mesmo confessa em "Diário Íntimo":

Desde menino, eu tenho a mania do suicídio. Aos sete anos, logo depois da morte de minha mãe, quando eu fui acusado injustamente de furto, tive vontade de me matar. Foi desde essa época que eu senti a injustiça da vida, a dor que ela envolve (...) Outra vez que essa vontade me veio foi aos onze anos ou doze, quando fugi do colégio. Armei um laço numa árvore lá do sítio da ilha, mas não me sobrou coragem para me atirar no vazio com ele ao pescoço. (...) Há dias que essa vontade me acompanha; há dias que ela me vê dormir e me saúda ao acordar. Estou com vinte e sete anos (BARRETO, 2001, p.17-18).

Se essas notas forem algum dia lidas, o que eu não espero, há de ser difícil explicar esse sentimento doloroso que eu tenho de minha casa, do desacordo profundo entre mim e ela; é de tal forma nuançosa a razão de ser disso, que para bem ser compreendido exigiria uma autobiografia, que nunca farei. Há coisas que, sentidas em nós, não podemos dizer. A minha melancolia, a mobilidade do meu espírito, o cepticismo que me corrói cepticismo que, atingindo as coisas e pessoas estranhas a mim, alcançam também a minha própria entidade - , nasceu da minha adolescência feita nesse sentimento da minha vergonha doméstica, que também deu nascimento a minha única grande falta (BARRETO, 2001, p. 12).

Pode-se perceber que a questão da exclusão social e do preconceito retratados propicia uma linguagem melancólica.

Fui a bordo ver a esquadra partir. Multidão. Contato pleno com meninas aristocráticas. Na prancha, ao embarque, a ninguém pediam convite; mas a mim pediram. Aborreci-me. Encontrei Juca Floresta. Fiquei tomando cerveja na banca e saltei. É triste não ser branco (BARRETO, p. 57).

Artaud (1993) diz que o "louco é um sujeito não ouvido em sua verdade". Assim, para aquele que foi considerado como louco pela sociedade, Lima Barreto conseguiu profetizar, mesmo que ironicamente, o preconceito racial que futuramente seria marcado 


\section{LAEBER, AP}

por uma das mais horrendas cicatrizes da história mundial. Em forma de confissão, percebemos essas ideias no seguinte trecho:

Vai se estendendo, pelo mundo, a noção de que há umas certas raças superiores e umas outras inferiores, e que essa inferioridade, longe de ser transitória, é eterna e intrínseca à própria estrutura de raça. Diz-se ainda mais que: que as misturas entre essas raças são um vício social, uma praga e não sei que cousa feia mais. Tudo isso se diz em nome da ciência e a coberto da autoridade de sábios alemães. [...] O que se diz em alemão é verdade transcendente. [...] Urge ver o perigo dessas idéias, para nossa felicidade individual e para nossa dignidade superior de homens. Atualmente, ainda não saíram dos gabinetes e laboratórios, mas, amanhã, espalhar-se-ão, ficarão à mão dos políticos, cairão sobre as rudes cabeças de massa, e talvez tenhamos de sofrer matanças, afastamentos humilhantes, e os nossos liberalíssimos verão uns novos judeus (BARRETO, p. 61-62).

Essa anotação foi feita quando o autor foi internado no Hospital Nacional dos Alienados em 1919. Barreto alertou através de seus discursos como a injustiça social seria agravada pela Segunda Guerra Mundial e pelas ideias totalitárias de Hitler. A questão apontada em sala de aula foi até que ponto uma pessoa pode ser considerada louca, já que, nesse período da história brasileira, uma das causas para a doença mental era a hereditariedade. Outro apontamento interessante levantado pelos alunos na leitura desse trecho foi o medo de Barreto de uma futura associação da raça à loucura.

Para entender a proposta da escrita de Lima Barreto, que rompia com os modelos de seu tempo, Alfredo Bosi (2006) julga necessário que saibamos que esse autor tem origem humilde, dos dilemas relacionados à sua cor, à vida penosa de jornalista e amuense pobre, à viva consciência de sua própria situação social.

Lima Barreto destacou em suas obras, e daremos preferência à “Diário Íntimo", por retratar a condição social daqueles que viviam à margem: negros, mulatos e pobres. Por isso, pode-se considerar como uma "Literatura militante", já que seu intuito era voltar-se contra o preconceito e as injustiças sociais. Observe o trecho a seguir:

Hoje, comigo, deu-se um caso que, por repetido, mereceu-me reparo. la eu pelo corredor afora, daqui do Ministério, e um soldado dirigiu-se a mim, inquirindo-me se era contínuo. Ora, sendo a terceira vez, a coisa feriu-me um tanto a vaidade, e foi preciso tomar-me de muito sangue frio para que não desmentisse com azedume. Eles, variada gente simples, insistem em tomar-me como tal, e nisso creio ver um formal desmentido ao professor Broca (de memória). Parece-me que esse homem afirma que a educação embeleza, dá, enfim, outro ar à fisionomia. Porque então essa gente continua a me querer contínuo, porque? Porque... o que é verdade na raça branca, não é extensivo ao resto; eu, mulato ou negro, como queiram, 
estou condenado a ser sempre tomado por contínuo. Entretanto, não me agasto, minha vida será sempre cheia desse desgosto e ele far-me-á grande. Era de perguntar se o Argolo, vestido assim como eu ando, não seria tomado por contínuo; seria, mas quem o tomasse teria razão, mesmo porque ele é branco. Quando me julgo - nada valho; quando me comparo, sou grande. Enorme consolo (BARRETO, 2001, p. 38).

Segundo Barbosa (1964, p.174), "a literatura, na sua concepção, tinha que ser militante, visando o objetivo certo e definido, e não uma 'literatura contemplativa'; [...] 'cheia de ênfase e arrebiques'; [...] falsa e sem finalidade".

Para o crítico Nicolau Sevcenko, Lima Barreto tinha como objetivo exprimir com bastante clareza as mazelas da sociedade. Assim, Sevcenko (2003, p. 168) relata que a missão da tessitura literária barretiana é fazer comunicar umas almas com as outras, é dar-lhes um perfeito entendimento entre elas, é ligá-las mais fortemente, reforçando a solidariedade humana.

Como é possível notar, o ambiente, seja ele externo ou interno, uma vez abalado, desestrutura àqueles que se veem à margem. A literatura combativa de Lima Barreto protesta as mazelas sofridas pelas pessoas menos favorecidas, e sob um viés militante, desabafa e denuncia os detalhes do cotidiano da sociedade carioca e retrata também 0 perfil de um brasileiro marginalizado.

\section{O hip hop de Emicida: Uma ponte entre passado e presente}

Em 17 de agosto de 1985, nasce na zona norte de São Paulo, Leandro Roque de Oliveira, natural da periferia do bairro de Cachoeira. Leandro tornou-se conhecido pela sua fluidez nas batalhas das rimas improvisadas. Na verdade, essa habilidade do improviso na arte do hip hop lhe deu o codinome Emicida, fusão das palavras "MC" e "homicida". Logo depois, Emicida cria uma sigla para seu próprio codinome: Enquanto Minha Imaginação Compuser Insanidades Domino a Arte (E.M.I.C.I.D.A).

Entre os latino-americanos, os jamaicanos e os afro-americanos da cidade de Nova York surge o hip hop nos anos de 1970 e consideram esse gênero musical como um movimento cultural. Para o criador deste movimento, Afrika Bombaataa, o hip hop invoca "Paz, União e Diversão". No dia 12 de novembro de 1973 Afrika funda a Zulu Nation ${ }^{4}$ fazendo desse dia como o nascimento do hip hop.

${ }^{4}[. .$.$] Bombaataa, ex-membro da Black Spades - gangue do South Bronx -, teve a iniciativa de articular as$ expressões presentes nas festas de rua - DJ, MC, break e grafite - num movimento mais amplo, o hip hop. 


\section{LAEBER, AP}

No Brasil o hip-hop surge aos poucos. Como afirma Bentes (2007, p. 124), o break ${ }^{5}$ vem como o primeiro item a ser agraciado pelos brasileiros, e com isso aparece os breakboys e suas respectivas gangues, que dos bailes iam às ruas. O break ganhava espaço na grande São Paulo, da mesma forma como o grafite se manifestava como arte e rebeldia. Assim para a autora,

[...] não é apenas como um gênero musical que o hip-hop se manifesta e pode ser definido. Sua linguagem poética é variada e apresenta uma mescla de grafite (com desenhos de protesto ou de marca de territórios de gangues ou ainda com frases de impacto), com a moda (caracterizada pelo estilo próprio de se vestir: camisetas longas, calças folgadas e bonés) e o verso ácido (identificado pelas redondilhas de rimas irregulares na voz de quem acompanha a batida ou pelo verso de improviso feito na disputa de free style) (BENTES, 2007, p. 125).

Na cultura hip hop, o rap ${ }^{6}$, em seu viés político, tem como característica transmitir a experiência e indignação dos negros perante a opressão. Este gênero musical transformou-se, ao longo do tempo, em poderoso veículo de expressão política (KELLNER, 2001).

O rap "Boa Esperança7" faz parte do disco "Sobre Crianças, Quadris, Pesadelos e Lições de Casa..." (2015), que foi produzido no período que Emicida esteve em uma viagem a Angola e Cabo Verde. Antes deste disco ser divulgado, Boa Esperança, com sete minutos de duração de vídeo, foi a primeira música que ganhou um clipe. Foi dirigido por Katia Lund e João Wainer, lançado no Youtube no dia 30 de junho de 2015 e com quase 3 milhões de visualizações.

A trama do vídeo recria a linha "Casa Grande \& Senzala", obra do sociólogo Gilberto Freyre, publicada primeiramente em 1933 e que apresenta a formação da sociedade brasileira: dominadores (brancos e ricos) são servidos pelos dominados

\footnotetext{
Inspirado por referências da luta por direitos civis nos Estados Unidos e preocupados com a situação de pobreza, opressão racial e violência juvenil nos guetos, fundou em 1973 a Universal Zulu Nation, primeiro coletivo de hip hop a mesclar elementos artísticos e conhecimentos políticos num trabalho comunitário. (LOUREIRO, 2016, p. 236).

${ }^{5} \mathrm{~A}$ dança Break é a arte corporal da cultura Hip-Hop e o breaker é o artista que dá vida à dança Break. O Break anuncia que sua função, enquanto linguagem artístico-corporal, é mostrar o discurso do corpo, na sua relação consigo mesmo e nas relações que se estabelecem entre o corpo e o real. (ALVES, 2004)

${ }^{6} \mathrm{O}$ rap - estilo musical nascido nos E.U.A, em meados das décadas de 80 e 90 - tem a denominação proveniente da expressão inglesa Rythm and Poetry (ritmo e poesia), pois consistia em rimar palavras sobre uma batida eletrônica.

${ }^{7}$ Essa música, transformada primeiramente em vídeo e composta por Emicida (letra), J Ghetto (refrão) e Nave (beat), foi batizada com o nome de um navio negreiro no livro "A Rainha Ginga", do angolano José Eduardo Agualusa.
} 


\section{LAEBER, AP}

(negros e pobres). Estes vivenciando o desprezo e o resto de uma sociedade massacrante.

Podemos observar que a letra de "Boa Esperança" expõe diversas situações constrangedoras suportadas pelos empregados. Temos como exemplo o assédio sexual e moral, que é retratado no seguinte trecho:

Cês diz que nosso pau é grande!

Espera até ver nosso ódio

Por mais que você corra, irmão

Pra sua guerra vão nem se lixar Esse é o xis da questão Já viu eles chorar pela cor do orixá?

A história de "Boa Esperança" representa, diante de um formato audiovisual, a questão do racismo abertamente. Um dos traços marcantes que há neste rap é o da "transtemporalidade", que de acordo com Soares (2004), numa "negociação entre o passado e presente está a consonância entre o refrão da música e a sequência lógica da história narrada em "Boa Esperança" (2015):

E os camburão o que são? Negreiros a retraficar

Favela ainda é senzala, jão Bomba relógio prestes a estourar

O tempero do mar foi lágrima de preto Papo reto como esqueletos de outro dialeto

Só desafeto, vida de inseto, imundo Indenização? Fama de vagabundo Nação sem teto, Angola, Keto, Congo, Soweto A cor de Eto'o, maioria nos gueto Monstro sequestro, capta-tês, rapta

Evidencia-se nesse excerto a alusão ao tráfico de escravos no Brasil, quando os negros eram trazidos da África nos porões dos navios negreiros. O enunciador constrói uma metáfora ao dizer que os "camburão" - compartimento traseiro fechado dos carros de polícia para transporte de pessoas presas -, são os atuais navios negreiros. Ou seja, o tráfico de escravos não acabou, pois esses "navios" continuam a "retraficar" os negros no Brasil, que continuam nas senzalas, que são atualmente as favelas.

Ademais, no trecho "O tempero do mar foi lágrima de preto", o enunciador estabelece uma intertextualidade com o poema "Mar Português", de Fernando Pessoa, que em seus versos diz "Ó mar salgado, quanto do teu sal; São lágrimas de Portugal" 


\section{LAEBER, AP}

(PESSOA, 1960). Nesse poema, o eu lírico faz uma crítica às grandes perdas provocadas pelas navegações portuguesas que, apesar de renderem a soberania nos mares à nação lusitana, provocaram inúmeras mortes de cidadãos portugueses em prol da ambição da conquista de novas terras. De maneira análoga, a canção de Emicida faz uma crítica ao tráfico de escravos que sob o argumento do desenvolvimento das colônias, destruíram inúmeras vidas e famílias. Talvez tenha ainda sido a escravidão muito pior, já que os africanos não eram considerados pessoas, mas "insetos", como afirma o rapper, que vinham para um outro país que não os acolhia como nação.

Essa leitura atenta deve ser praticada em sala de aula para que nossos alunos reconheçam os diferentes discursos que são produzidos a partir da história, já que muito se fala sobre a soberania marítima dos portugueses, mas pouco sobre os prejuízos humanos e sociais dessa atitude. Do mesmo modo, é preciso reconhecer como a escravidão, com o fim histórico no século XIX, continua tão forte nos dias atuais, ou quiçá mais grave, já que saímos de um cativeiro e uma sujeição explícitos para implícitos.

O traço "transtemporal" da canção continua no fragmento:

Violência se adapta, um dia ela volta pucêis Tipo campos de concentração, prantos em vão

Quis vida digna, estigma, indignação O trabalho liberta (ou não) Com essa frase quase que os nazi, varre os judeu - extinção

A menção de "violência se adapta" direciona para as alusões que virão em seguida quando o enunciador menciona o acontecimento da Segunda Guerra Mundial ao usar as expressões "campos de concentração", "trabalho liberta", "nazi" e "judeu”. A citação do nazismo surge para comparar o argumento da força de trabalho usada durante a Guerra e no momento pós escravidão para convencer as minorias sociais - negros e judeus - que o trabalho seria a libertação das escravidões. Contudo, quando se pensa no contexto escravocrata brasileiro, lembramos que a relação entre os donos das propriedades e exescravos era de total submissão, já que esses últimos não tinham para onde ir. Noutros termos, a "liberdade" afiançada pela lei Áurea não garantiu a liberdade na prática e, assim como os judeus, os escravos foram enganados.

Além da imagem aparente na letra de Emicida, há uma forte evidência quanto ao assunto espaço. Seguindo a ideia da obra de Freyre (1933), a oposição casa-grande e senzala fica aparente no vídeo quando os convidados e donos da casa (casa grande - 


\section{LAEBER, AP}

propriedade dos brancos) não interagem com os empregados da cozinha (senzala). Observe essa divisão de ambientes:

Depressão no convés

Há quanto tempo nóiz se fode e tem que rir depois

Pique Jack-ass, mistério tipo lago Ness

Sério és, tema da faculdade em que não pode por os pés

Vocês sabem, eu sei

Que até Bin Laden é made in USA

Tempo doido onde a KKK, veste Obey (é quente mesmo)

Pode olhar num falei?

Nessa equação, chata, policia mata? Plow! Médico salva? Não! Por que? Cor de ladrão.

Nessa estrofe, o enunciador constrói diversas críticas ao dizer que a questão negra é apenas tema para debate na academia, que está repleta de brancos falando sobre negros. A escravidão, o racismo, o preconceito são "tema da faculdade", lugar esse que o negro não pode pôr os pés da mesma forma que no negro não podia colocar os pés no convés do navio negreiro. Ou seja, "Há quanto tempo nóiz se fode?". E continua a discussão estendendo a crítica aos USA, nação que influencia o pensar e o consumismo nos países latino-americanos, com séries, filmes, jornalismo, marcas de vestuário e etc. promovendo o sentimento capitalista acima de qualquer coisa. É o olhar norte-americano que imprimi valor à vida em sociedade no Brasil e isso faz com que verdadeiras guerras financiadas por eles não sejam questionadas pelo resto do mundo, como a criação do monstro Bin Laden pela mídia USA, por exemplo.

Nessa perspectiva, o negro no Brasil será visto como alguém perigoso, ou menos humano. Por isso, cotidianamente vidas negras são abatidas sem 0 menor questionamento. Abatidas pela polícia e ignoradas pelos médicos, já que o ladrão tem cor.

Nessa linha de raciocínio, é imprescindível que os professores de línguas promovam o senso e a argumentação crítica a partir das inferências feitas na leitura do rap. É importante mostrar aos alunos que, mesmo que haja indignação pela população a respeito da violência relacionada ao preconceito racial, ainda há aqueles que não toleram a inserção de pessoas de cor e/ou nível social diferente. Um exemplo disse é a nítida segregação racial das profissões elitizadas em nosso país, como engenharia, médica, advocacia, que impedem que os negros cheguem ao convés da sociedade.

Embora o governo nos últimos anos tenha investido em programas de integração social, que permitem o acesso às faculdades, tais como, SiSu, ProUni, Fies e Escola da 


\section{LAEBER, AP}

Família, ainda há uma grande quantidade de brancos e ricos em universidades públicas e federais, que desfrutam do ensino público de qualidade e, especialmente, dos cursos elitizados.

Ademais, a leitura atenta da canção permite-nos discutir como a cultura americana está cravada no dia a dia do cidadão brasileiro, impondo políticas, economias, enfim, o modo branco e norteamericano de pensar que institui lugares muito bem marcados entre ricos e pobres, brancos e negros.

$\mathrm{Na}$ perspectiva de Rose (1994), a composição de Leandro Roque tem como característica $O$ ato de enfrentar 0 racismo, resistindo àquilo que podemos chamar de "mito da democracia racial", crítica inclusive feita em relação à obra de Gilberto Freyre. O discurso da canção foi construído como aquele que opera a partir de uma politização, que não se caracteriza necessariamente pelo discurso do enfrentamento aberto, mas pela veiculação das interpretações sociais outras que não as hegemônicas.

Portanto, podemos entender que, como Lima Barreto, Emicida através de seus raps produz uma estética subversiva disfarçada, parte de um discurso oculto, criticando e resistindo a vários aspectos da dominação social (ROSE, 1994).

\section{CONSIDERAÇÕES FINAIS}

Buscamos salientar como as intempéries sociais - que marcaram a trajetória do autor pré-modernista e do rapper Emicida - transformaram suas experiências e indignações em uma literatura combativa, que protesta as mazelas sofridas pelas pessoas menos favorecidas, e sob um viés militante, desabafam e denunciam os detalhes do cotidiano da sociedade, retratando também o perfil de um brasileiro marginalizado.

Procuramos sugerir esses textos, como propostas de atividades de leitura para os alunos, a fim de que eles não fiquem apenas na superficialidade, mas aprofundem-se mais nas leituras, buscando entender e/ou identificar os discursos ou ideologias que estão por trás de ambas escritas, remetendo-se, prioritariamente, para a forma como a sociedade brasileira se vê e é vista, sobretudo no que diz respeito aos problemas sociais.

Assim, concluiu-se que o professor de Literatura deve propiciar esses momentos de leitura não só dos clássicos, mas de outros gêneros textuais também, procurando estabelecer diálogos entre textos distintos estruturalmente, mas semelhantes quanto ao conteúdo e intenção. 


\section{LAEBER, AP}

Ainda, visto que "a literatura foi (e ainda é) uma das linguagens através das quais diferentes comunidades constroem, reforçam ou reformatam sua identidade, desdobram e renovam poderes da linguagem verbal" (LAJOLO, 1996, p.108) o professor precisa instigar em seu aluno à leitura crítica, polissêmica, aquela em que o leitor é capaz de adentrar no texto e dele extrair múltiplos ensinamentos para a vida.

A leitura na sala de aula é importante e indispensável, pois prepara os alunos para o futuro. Ela, quando conduzida de maneira correta, pode gerar resultados muito positivos, mas quando prazerosa pode gerar mudanças. A leitura muda pessoas, forma cidadãos!

\section{REFERÊNCIAS}

ALTHUSSER, L. Aparelhos ideológicos do estado. Presença, Lisboa, 1974.

ALVES, F.S. A dança Break: corpos e sentidos em movimento no Hip-Hop. Motriz, Rio Claro, v. 10, n. 1, p. 01-07, jan./abr. 2004

ARTAUD, Antonin. Van Gogh, o suicidado da sociedade. Tradução de Aníbal Fernandes. Lisboa: Hiena, 1993.

BAKHTIN, M. Estética da criação verbal. 4 ed. São Paulo: Martins Fontes, 2003.

BARBOSA, Francisco de Assis. A vida de Lima Barreto. 7ª ed. - São Paulo: Itatiaia, 1988.

BARRETO, Lima. Diário Íntimo - Fragmentos. 2ª ed. Porto Alegre: Mercado Aberto, 2001.

BENTES, A.C.; FERNANDES, F. A poesia oral nas bordas do mundo: identidades em movimentos nos videoclipes brasileiros de rap. In: Oralidade e literatura 3: outras veredas da voz. LEITE, Eudes Fernandes, FERNANDES, Frederico. (orgs.). Londrina: EDUEL, 2007.

BOSI, Alfredo. História concisa da literatura brasileira. 43. ed. - São Paulo: Cultrix, 2006.

CUTI. A consciência do impacto nas obras de Cruz e Sousa e de Lima Barreto. Belo Horizonte: Autêntica Editora, 2009

EMICIDA. Pra quem Já Mordeu um Cachorro Por Comida, Até Que Eu Cheguei Longe. São Paulo: Laboratório Fantasma, 2009, 1 CD . Emicidio. São Paulo: Laboratório Fantasma, 2010, 1 CD

. O Glorioso Retornode Quem Nunca Esteve Aqui. São Paulo: Laboratório Fantasma, 2013, 1 CD

Sobre Crianças, Quadris, Pesadelos e Lições de Casa... . São Paulo: Laboratório Fantasma/Sony Music, 2015, 1 CD 
FREYRE, Gilberto. Casa Grande \& Senzala. Rio de Janeiro: Maia e Schmidt, 1933.

FOUCAULT, Michel. A escrita de si. In: O que é um autor? Lisboa: Passagens. 1992. pp. 129-160.

GONZAGA, Sergius. Curso de literatura brasileira. 4 Ed. - Porto Alegre: Leitura XXI, 2010.

HIDALGO, Luciana. Literatura de urgência: Lima Barreto no domínio da loucura. São Paulo: Annablume, 2008.

KELLNER, D. A cultura da mídia. 1 ed., São Paulo, EDUSC, 454 p., 2001.

LAJOLO, Marisa. Oralidade, um Passaporte para a Cidadania Literária Brasileira. In GUIMARÃES, Eduardo e ORLANDI, Eni Puccinelli. (org.). Língua e Cidadania $O$ Português do Brasil. Campinas: Pontes, 1996.

LOUREIRO, Braulio R. C. Arte, cultura e política na história do rapnacional. Revista do Instituto de Estudos Brasileiros, São Paulo, N. 63, p.235-241, Abr 2016.

MUSSALIM, Fernanda. Análise do Discurso. In MUSSALIM, Fernanda e BENTES, Anna Cristina (org.) Introdução à linguística: domínios e fronteiras. Volume 2. p. 101 - 142. São Paulo: Cortez, 2006.

ORLANDI, Eni P. Análise do discurso: princípios e procedimentos. 6 ed. Campinas, SP: Pontes, 2005.

2007.

Análise do discurso: princípios e procedimentos. 7 ed. Campinas, SP: Pontes, Discurso e leitura. $3^{a}$. ed. Campinas: Cortez, 1996.

PÊCHEUX, M. Semântica e Discurso - uma crítica à afirmação do óbvio. Campinas, Editora da Unicamp, 2000. 14.

mimeo, 2000

Remontemos de Foucault a Spinoza. Trad. Brasileira de GREGOLIN, M.R,

ROSE, T. Black noise: Rap musicand black culture in contemporary America. Ed., Middletown, Wesleyan, 257 p. 1994.

PESSOA, Fernando. Mar Português. Obra poética, 1960.

SEVCENKO, Nicolau. Literatura como missão: tensões sociais e criação cultural na Primeira República. 2. Ed. - São Paulo: Companhia das Letras, 2003.

SOARES, T. 2004. Videoclipe, o elogio da desarmonia: Hibridismo, transtemporalidade e neobarroco em espaços de negociação. In: Intercom, Porto Alegre, 2004.

SOUZA, R. A.; FACHIN, P. C. Um breve estudo: análise do discurso francesa no gênero textual propaganda. In.: II Seminário Nacional em Estudos da Linguagem: Diversidade, Ensino e Linguagem. UNIOESTE - Cascavel / PR, 2010, p. 1-10.

SUSIN, C. O rap como resistência no contexto escolar. 2015 


\title{
Como citar este artigo (ABNT)
}

LAEBER, A. P. Uma leitura além da margem: diálogos entre a escrita de Lima Barreto e o hip hop de Emicida nos entornos da sala de aula. SELL, Uberaba, MG, v. X, n. X, p. XXX-XXX, 2019. Disponível em: <inserir link de acesso>. Acesso em: inserir dia, mês e ano de acesso. DOI: inserir link do DOI.

Como citar este artigo (APA)

Laeber, A.P (2019). Uma leitura além da margem: diálogos entre a escrita de Lima Barreto e o hip hop de Emicida nos entornos da sala de aula. SELL, X(X), XXX-XXX. Recuperado em: inserir dia, mês e ano de acesso de inserir link de acesso. DOI: inserir link do DOI.

\begin{abstract}
ANEXO 1
Letra e interpretação de Emicida, refrão de J Ghetto e beat de Nave

\section{Boa Esperança}

Por mais que você corra, irmão

Pra sua guerra vão nem se lixar

Esse é o xis da questão

Já viu eles chorar pela cor do orixá?

E os camburão o que são?

Negreiros a retraficar

Favela ainda é senzala, Jão!

Bomba relógio prestes a estourar

O tempero do mar foi lágrima de preto

Papo reto como esqueletos de outro dialeto

Só desafeto, vida de inseto, imundo

Indenização? Fama de vagabundo

Nação sem teto, Angola, Keto, Congo, Soweto

A cor de Eto'o, maioria nos gueto

Monstro sequestro, capta-tês, rapta

Violência se adapta, um dia ela volta pucêis

Tipo campos de concentração, prantos em vão

Quis vida digna, estigma, indignação

O trabalho liberta (ou não)

Com essa frase quase que os nazi, varre os judeu - extinção

Depressão no convés

Há quanto tempo nóiz se fode e tem que rir depois

Pique Jack-ass, mistério tipo lago Ness

Sério és, tema da faculdade em que não pode por os pés

Vocês sabem, eu sei

Que até Bin Laden é made in USA 


\section{LAEBER, AP}

Tempo doido onde a KKK, veste Obey (é quente memo)

Pode olhar num falei?

Aê, nessa equação, chata, polícia mata - Plow!

Médico salva? Não!

Por quê? Cor de ladrão

Desacato, invenção, maldosa intenção

Cabulosa inversão, jornal distorção

Meu sangue na mão dos radical cristão

Transcendental questão, não choca opinião

Silêncio e cara no chão, conhece?

Perseguição se esquece? Tanta agressão enlouquece

Vence o Datena com luto e audiência

Cura, baixa escolaridade com auto de resistência

Pois na era Cyber, cêis vai ler

Os livro que roubou nosso passado igual alzheimer, e vai ver

Que eu faço igual burkinafaso

Nóiz quer ser dono do circo

Cansamos da vida de palhaço

É tipo Moisés e os Hebreus, pés no breu

Onde o inimigo é quem decide quando ofendeu

(Cê é loco meu!)

No veneno igual água e sódio (vai, vai, vai)

Vai vendo sem custódio

Aguarde cenas no próximo episódio

Cês diz que nosso pau é grande

Espera até ver nosso ódio

Por mais que você corra, irmão

Pra sua guerra vão nem se lixar

Esse é o xis da questão

Já viu eles chorar pela cor do orixá?

E os camburão o que são?

Negreiros a retraficar

Favela ainda é senzala, Jão

Bomba relógio prestes a estourar 